\title{
The worst nightmare in the catheterization laboratory without on-site cardiac surgery - case report of two patients with coronary artery perfora- tion with guiding wire
}

Đeiti Prvulović*, Irzal Hadžibegović, Božo Vujeva, Krešimir Gabaldo

General Hospital "Dr J. Benčević, Slavonski Brod, Croatia

The first patient: AP CCSC III one month before admission. At diagnostic coronary angiography: ostial occlusion of $L A D$, well collateralized from CxA which departs from the right coronary sinus. Description of the procedure - CTO recanalization complicated with perforations of distal LAD and the development of tamponade.

Second patient: elective intervention on in-stent restenosis of bifurcation lesion, perforation and tamponade complicated with cardiogenic shock and resuscitation.

Authors review possible solutions to this rare and potentially fatal complication, with the specifics of the decision mak- ing process as it occurs without the possibility of emergency transport of patients to cardiac surgeon.

KEYWORDS: coronary artery disease, percutaneous coronary intervention, in-stent restenosis.

\section{Received: $5^{\text {th }}$ Mar 2013}

*Address for correspondence: Andrije Štampara 42, HR-35000 Slavonski Brod, Croatia.

Phone: +385-35-201-201

E-mail: deiti. prvulovic@sb.t-com.hr 